\title{
Source Properties of Earthquakes near the Salton Sea Triggered by the 16 October 1999 M 7.1 Hector Mine, California, Earthquake
}

\author{
by Susan E. Hough and Hiroo Kanamori
}

\begin{abstract}
We analyze the source properties of a sequence of triggered earthquakes that occurred near the Salton Sea in southern California in the immediate aftermath of the M 7.1 Hector Mine earthquake of 16 October 1999. The sequence produced a number of early events that were not initially located by the regional network, including two moderate earthquakes: the first within $30 \mathrm{sec}$ of the $P$-wave arrival and a second approximately 10 minutes after the mainshock. We use available amplitude and waveform data from these events to estimate magnitudes to be approximately 4.7 and 4.4, respectively, and to obtain crude estimates of their locations. The sequence of small events following the initial $M 4.7$ earthquake is clustered and suggestive of a local aftershock sequence. Using both broadband TriNet data and analog data from the Southern California Seismic Network (SCSN), we also investigate the spectral characteristics of the $M 4.4$ event and other triggered earthquakes using empirical Green's function (EGF) analysis. We find that the source spectra of the events are consistent with expectations for tectonic (brittle shear failure) earthquakes, and infer stress drop values of 0.1 to $6 \mathrm{MPa}$ for six $M 2.1$ to $M 4.4$ events. The estimated stress drop values are within the range observed for tectonic earthquakes elsewhere. They are relatively low compared to typically observed stress drop values, which is consistent with expectations for faulting in an extensional, high heat flow regime. The results therefore suggest that, at least in this case, triggered earthquakes are associated with a brittle shear failure mechanism. This further suggests that triggered earthquakes may tend to occur in geothermal-volcanic regions because shear failure occurs at, and can be triggered by, relatively low stresses in extensional regimes.
\end{abstract}

\section{Introduction}

The $M_{\mathrm{w}} 7.31992$ Landers, California, earthquake produced the first unambiguous evidence that large earthquakes can trigger small events at regional distances, well outside the range of conventional aftershocks (e.g., Hill et al., 1993; Bodin and Gomberg, 1994). A similar burst of regional seismicity followed the 16 October $1999, M_{\mathrm{w}} 7.1$ Hector Mine, California earthquake (Gomberg et al., 2001; Glowacka et al., 2002). In both cases, triggered seismicity was observed to occur preferentially, although not exclusively, in active geothermal and volcanic regions such as Long Valley Caldera, The Geysers, and the Salton Sea region (Fig. 1). Although the M 5.4 Little Skull Mountain earthquake (Bodin and Gomberg, 1994) was a conspicuous exception, the concentration of remotely triggered earthquakes in geothermal and volacanic regions led researchers to consider triggering mechanisms that involve crustal fluids. A number of theoretical investigations have proposed triggering mechanisms that involve the effects of seismic waves on bubbles within fluid systems, such as advective overpressure (Linde et al.,
1994) and rectified diffusion (Sturtevant et al., 1996; Brodsky et al., 1998).

However, to date there has been very little investigation of the source properties of remotely triggered earthquakes. We do not know if they are ordinary tectonic (i.e., shear failure) earthquakes, or if they instead show evidence of a fluid-controlled source process such as anomalous focal mechanisms or radiated spectra. Such evidence can be subtle. Hough et al. (2000) recently presented spectral evidence of a fluid-controlled source process for (nontriggered) earthquakes in the Long Valley region, and the waveforms of these events were shown to be unremarkable at first glance. (Available data were insufficient to investigate possible nondouble-couple components to their focal mechanisms.)

Analysis of source properties of triggered earthquakes is likely to be hampered by data limitations. Resolution of source spectra of small earthquakes is always difficult because of the difficulty in independently distinguishing source, path, and site effects. In recent years, empirical 
Green's function analysis has emerged as the best approach to isolate source properties from complex path and site effects (e.g., Mueller, 1985; Frankel et al., 1986); however, the method requires waveform data with both high dynamic range and a large frequency bandwidth. Such data are not always available. Moreover, triggered earthquakes often occur immediately following large mainshocks or within highly active local clusters, so their waveforms are often not recorded cleanly.

The 1999 triggered earthquakes near the Salton Sea occurred near the southern termination of the San Andreas fault, an area that is well instrumented by the Southern California Seismic Network (SCSN) and, in recent years, by TriNet. In this study, we use data from both types of stations to investigate the source properties of earthquakes triggered (at regional distances) by the Hector Mine mainshock. The early triggered events occurred very close to one TriNet station, SSW (Fig. 1), which recorded on-scale broadband and strong-motion data for earthquakes of $M 2.6$ to 4.7.

\section{Data and Analysis}

The Hector Mine mainshock produced an energetic sequence of remotely triggered earthquakes near the Salton Sea, with dozens of events occurring within the first few hours (Fig. 2). The first identifiable triggered earthquake in the Salton Sea region is evident in the strong-motion record from station SSW (Fig. 3a). It occurred within $30 \mathrm{sec}$ of the $P$-wave arrival at this location, and its waveform dominates the mainshock acceleration record even at low frequencies. This earthquake, hereinafter referred to as E1, was not located by the network because the onset of the event cannot be distinguished amidst the mainshock coda at other stations. However, the $S-P$ time at SSW (approximately $1.7 \mathrm{sec}$ ) can be used to estimate the distance of the earthquake from this station. Using a simple layered velocity structure constructed from the crustal model of Fuis et al. (1982) and the shallow shear wave velocity model determined for the upper $100 \mathrm{~m}$ by Barker and Stevens (1983), the observed $S-P$ time implies a horizontal distance of 1-3 $\mathrm{km}$ for assumed event depths of 3-5 km. Based on this, and the relatively weak amplitudes of E1 observed at station BBB (see Figs. 1 and $3 \mathrm{a}$ ), we conclude that the event was within a few kilometers of station SSW. Comparing the peak amplitude of E1 with that of a (network-located) $M 4.0$ Salton Sea event (E3; see Table 1) that occurred approximately an hour after the mainshock, we estimate a magnitude of approximately 5.1 for event E1 if we assume that E3 and E1 occurred at the same location. If we assume that E1 occurred closer to station SSW, a somewhat lower estimate would result. Based on the suggestion that E1 did occur very close to SSW, and based also on the amplitudes of the earthquake at other TriNet stations (K. Hutton, personal comm., 2000), we obtain a preferred estimate of 4.7 .

It is interesting to note that the shaking from the $M 4.7$ triggered event dominates the mainshock strong-motion rec-

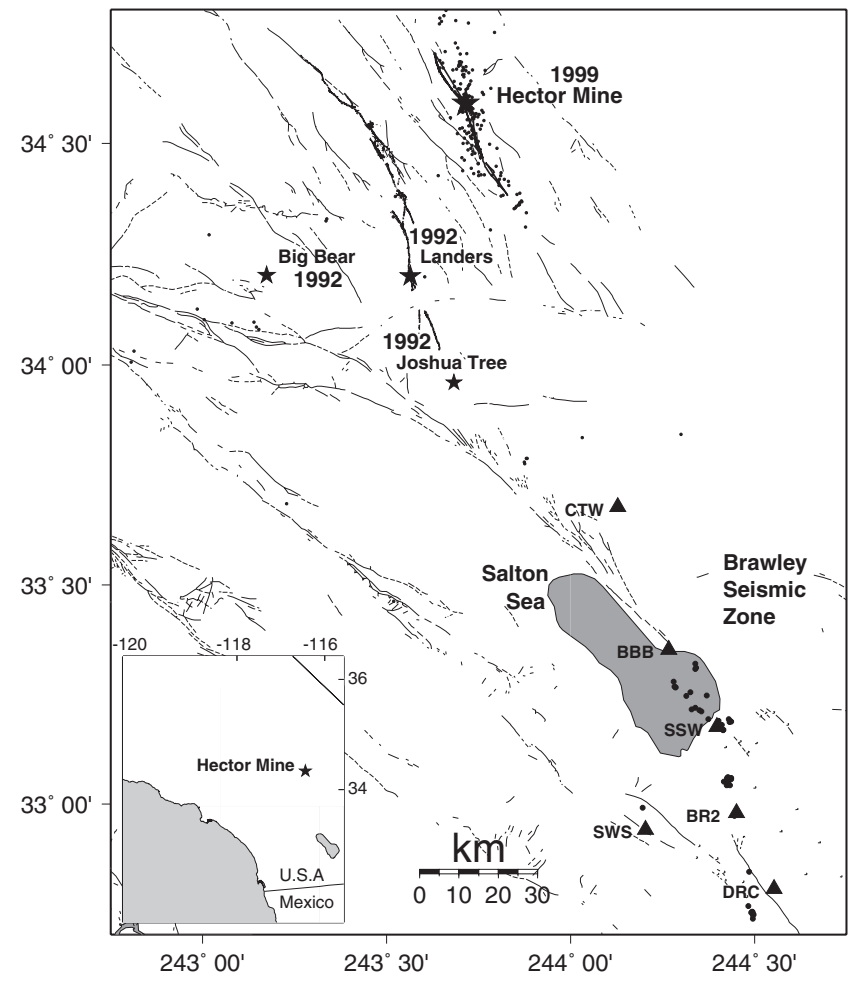

Figure 1. Map showing locations of Hector Mine mainshock and principal earthquakes from the 1992 Landers sequence (stars), early Hector Mine aftershocks (small circles), and remotely triggered earthquakes near the Salton Sea (medium circles). SCSN and TriNet stations used in this study (except for IKP, which is outside map area at $32.65 \mathrm{~N}, 116.11 \mathrm{~W}$ ) are also shown (triangles).

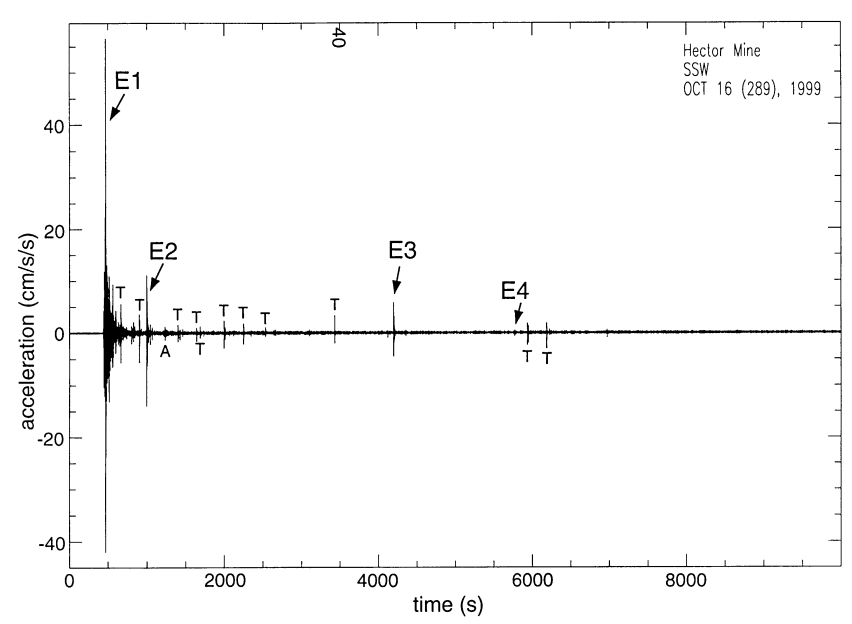

Figure 2. Continuous data recorded at station SSW for approximately 2.75 hours following the Hector Mine mainshock. The broadband velocity trace is demeaned and integrated to obtain acceleration. Triggered events analyzed in this study are indicated (see Table 1); other (inferred) local triggered events are indicated with Ts. Many more smaller local events can be seen. A magnitude 5.8 Hector Mine aftershock is also indicated (A). 
(a)
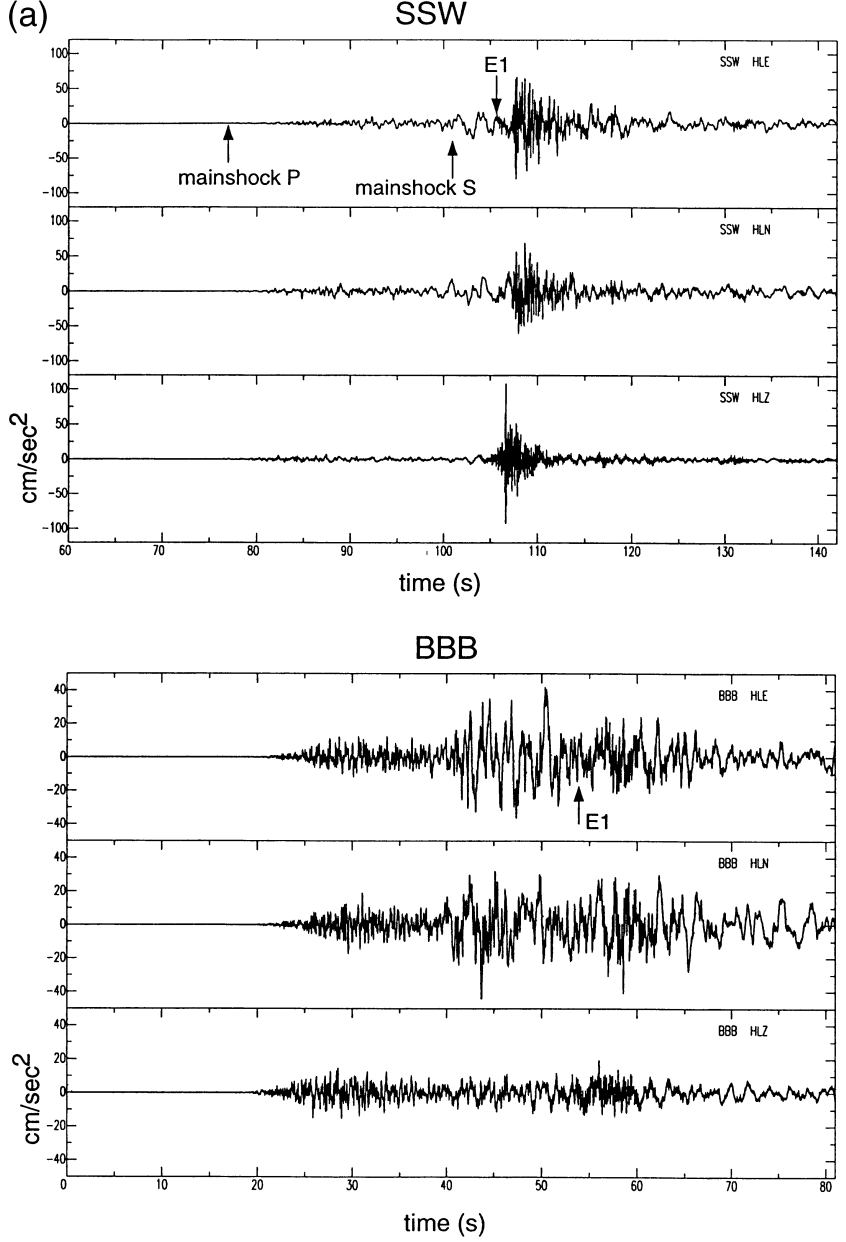

(b)
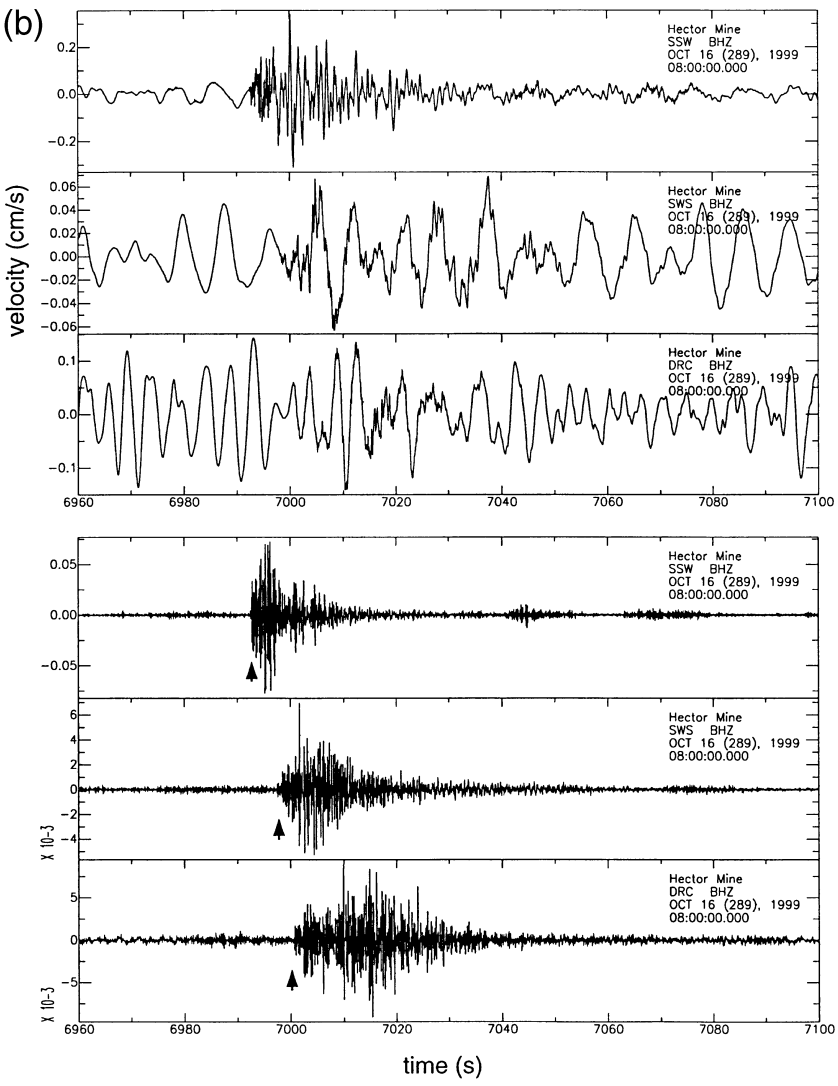

Figure 3. (a) Three components of strong motion data (acceleration in $\mathrm{cm} / \mathrm{sec}^{2}$ ) recorded at station SSW (top panel) and BBB (bottom panel) for the Hector Mine mainshock. At SSW, the inferred triggered earthquake is apparent even without filtering. The event can also be seen at BBB, although its amplitude relative to the mainshock arrivals is much lower. Arrows in bottom panel indicate initiation of triggered earthquake record. (b) Broadband vertical component recordings of event E2 from TriNet stations SSW, SWS, and DRC. Top set of traces show unfiltered velocity; bottom set shows time series highpass filtered above $5 \mathrm{~Hz}$. Arrows indicate first arrivals at all three stations, which are observed to be fairly clean. A magnitude of 4.4 is estimated for this event based on its amplitudes at SSW.

ord at station SSW. The Hector Mine ShakeMap (Scientists of the USGS et al., 2000) reveals an isolated lobe of high shaking $(\approx 0.1 \mathrm{~g})$ in the vicinity of station SSW. Because this lobe is entirely controlled by the recording at SSW, Figure 3a shows that it is controlled by the triggered event rather than the Hector Mine mainshock.

A second large triggered earthquake (hereinafter E2) occurred approximately 10 minutes after the mainshock. This earthquake was also not initially located by the network, but it is evident on the broadband recordings at SSW and other stations (Fig. 3b). Its pattern of arrival times at the stations shown in Figure $3 b$ is very similar to that of event E3, and so its location is assumed to be the same. An amplitude comparison with event E3 yields a magnitude estimate of 4.6 for event E2. An analysis of network data from other stations yields a similar value, $M 4.4$ (K. Hutton, personal comm., 2000).

To investigate the source spectra of the larger triggered earthquakes we use a frequency-domain empirical Green's function (EGF) deconvolution method. This approach provides a correction for whole-path attenuation and site response, but does not seek to recover the source time function. Although an ideal EGF event is very close to the larger earthquake being investigated, the frequency-domain approach will be fairly insensitive to the separation between the two events (e.g., Hough and Dreger, 1995). The only requirement is that the attenuation at depth over the distance of the separation be low compared to the near-surface attenuation that is common to recordings of both earthquakes at a given site. Therefore, even though the locations of events E1 and 
Table 1

Events Analyzed

\begin{tabular}{cccclllll}
\hline Event & Month & Day & $\mathrm{Hr}$ & Latitude & Longitude & $M$ & $f_{\mathrm{c}}(\mathrm{Hz})$ & $\sigma$ \\
\hline E1 & 10 & 16 & 0947 & $33.18^{*}$ & $-115.60^{*}$ & $4.7^{*}$ & - & 0.023 \\
E2 & 10 & 16 & 0956 & $33.18^{*}$ & $-115.60^{*}$ & $4.4^{*}$ & 0.7 & 0.35 \\
E3 & 10 & 16 & 1049 & 33.26 & -115.67 & 4.0 & - & - \\
E4 & 10 & 16 & 1115 & $33.22^{*}$ & $-115.67^{*}$ & $2.1^{*}$ & 5.6 & 0.1 \\
E5 & 10 & 16 & 1634 & 33.27 & -115.72 & 2.2 & 5.8 & 0.1 \\
E6 & 10 & 16 & 1748 & 33.27 & -115.72 & 3.5 & 3.0 & 1.3 \\
E7 & 11 & 15 & 1346 & 33.17 & -115.59 & 2.1 & 17.5 & 2.0 \\
E8 & 11 & 18 & 1029 & 33.17 & -115.60 & 3.5 & 5.0 & 5.8 \\
\hline
\end{tabular}

Event number, month, day, hour, and minute (UTC) of event. Magnitudes of E1, E2, and E4 are estimated from amplitude comparison with other events; other magnitudes are from SCSN catalog. $f_{\mathrm{c}}$ and $\sigma$ are corner frequencies and stress drops (in MPa) determined from Empirical Green's Function analysis. For event E1, stress drop is estimated from the inferred rupture dimension as estimated from the early aftershock distribution.

*Locations and magnitudes shown with asterisks represent estimated values (see text).

E2 are imprecise, we identify a later, smaller triggered event (E4; see Table 1) as an EGF event. This event occurred approximately an hour and a half after the mainshock, and is observed to have a waveform similar to that of E2.

Before performing a deconvolution to obtain a source spectrum for event E1 or E2, it is necessary to ascertain how much each signal is contaminated by the coda of earlier events. Figure 4 presents a Fourier transform of the signal from a window $10 \mathrm{sec}$ before each earthquake compared to the spectra for a 10-sec window encompassing the first arrivals. For E1, which was triggered by the highest-amplitude surface waves from the mainshock, the event spectrum is higher than the pre-event spectrum between 0.05 and $0.4 \mathrm{~Hz}$. This energy could result from either the continuing mainshock (surface wave) signal or from the triggered event itself. It is therefore impossible to distinguish the corner frequency of this event with any precision.

As an alternative approach to investigate the rupture dimension and stress drop of event E1, we consider the spatial distribution of the earthquakes that followed E1 within the first 24 hours. Hough (2000) has shown that early aftershock distributions for moderate ( $M$ 5-6) mainshocks are often clustered and suggestive of a mainshock rupture dimension, and that rupture dimensions estimated this way appear to be consistent with those obtained using other methods. Figure 5 shows the locations of the early Salton Sea events as determined by standard network processing. They are suggestive of a 12-13-km lineament oriented NW-SE beneath the Salton Sea, following the trend of the Brawley Seismic Zone. Assuming a circular rupture, this implies a rupture radius of approximately $6 \mathrm{~km}$.

The spectrum for event E2 is above that of the pre-event noise for all frequencies above approximately $0.25 \mathrm{~Hz}$ (Fig. 4). The event spectrum at lower frequencies is also not elevated with respect to that of the pre-event spectrum. This suggests that the corner frequency is higher than $0.25 \mathrm{~Hz}$, and that the data should be sufficient to resolve it using an empirical Green's function approach. To determine a decon-
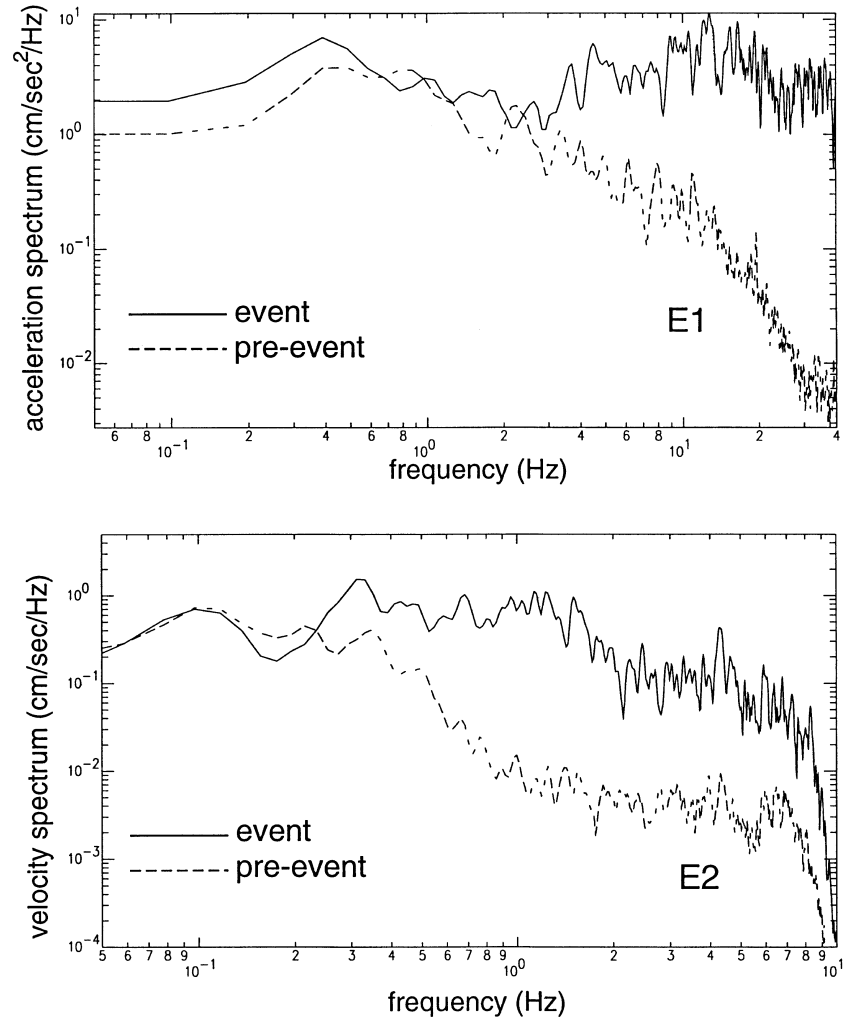

Figure 4. Solid lines indicate Fourier spectra of events E1 (top panel) and E2 (bottom panel) recorded at station SSW compared to spectra from a pre-event window of the same length (dotted lines). For E2 we use the broadband data (velocity); spectrum for event E1 is calculated from the strong motion data (acceleration) because the broadband channels are clipped.

volved source spectrum, we calculate Fourier spectra using windows $30 \mathrm{sec}$ long bracketing the main $S$-wave arrival on all three components. The signals are demeaned and tapered prior to spectral estimation. The spectra are smoothed using a recursive Hanning window, then deconvolved. The decon- 


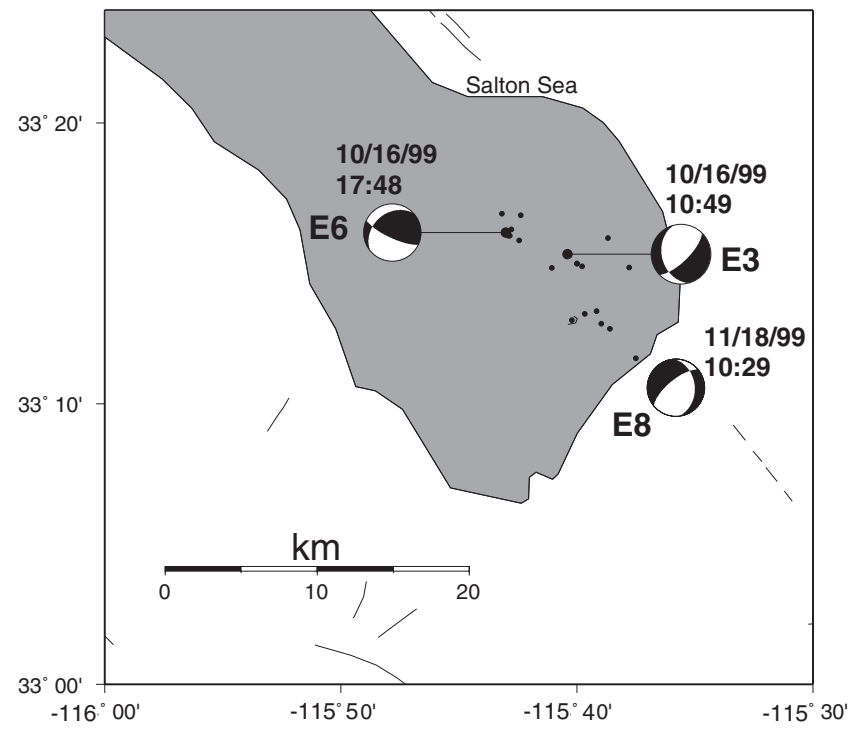

Figure 5. Map showing location of triggered events that occurred within 24 hours of the Hector Mine mainshock (small circles). If the events following E1 are aftershocks of the initial M 4.7 triggered event, then a rupture dimension of approximately $12-13 \mathrm{~km}$ is inferred. Also shown are first-motion focal mechanisms for events E3, E6, and E8. Station SSW, at which a very short $S-P$ time is inferred for events E1 and E2, is located almost immediately below event E8.

volved source spectra from all three channels are found to be similar and are averaged to obtain a final source spectrum for this event (Fig. 6).

We perform a similar analysis to obtain source spectra data for two smaller earthquakes, one (M 3.5) that occurred at 17:48 UTC on 16 October 1999, and another (M 3.5) that occurred at 10:29 UTC on 18 November 1999 (E6 and E8, respectively; Table 1). For these deconvolutions, a nearby M 2-2.2 event is used as an empirical Green's function. For the 16 October 1999 event, suitable (vertical component) data are available from three low-gain SCSN stations. We therefore follow the above procedure to obtain deconvolved source spectra at each station, then compute an amplitudenormalized average using the results from all stations. For the 18 November 1999 event, we use strong-motion data from the N-S component at station SSW (the amplitude of the E-W component of event E8 is extremely low). The resulting spectra are shown in Figure 6.

\section{Results}

The spectra shown in Figure 6 are observed to be consistent with a one-corner, omega-square shape (Brune, 1970) - a model that has been shown to fit the spectra of many small (shear failure) earthquakes (e.g., Walter et al., 1988; Hough and Dreger, 1995). We estimate corner frequencies for the events analyzed by fitting the observed de-
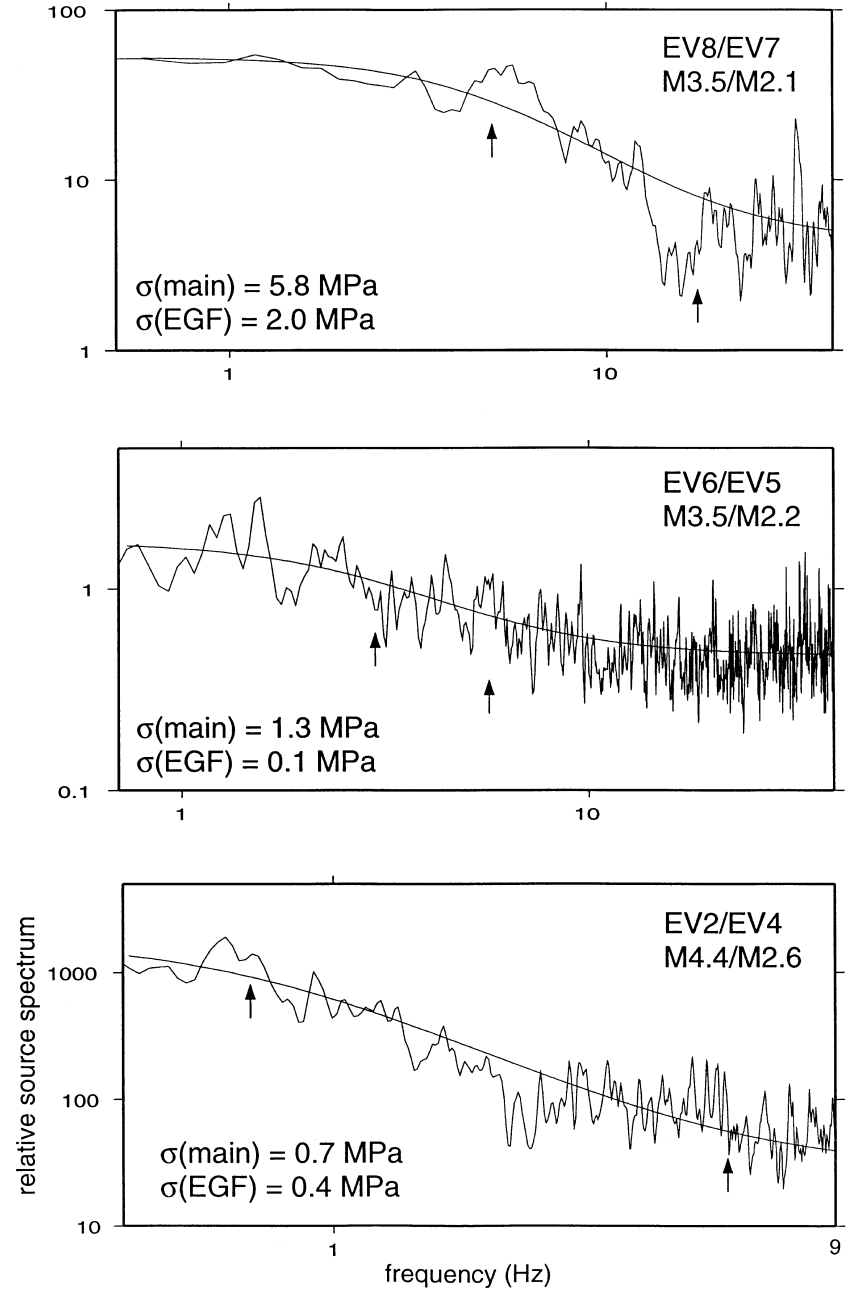

Figure 6. Deconvolved source spectra for events E2 (bottom), E6 (middle), and E8. Magnitudes of events and respective EGF events are shown in each panel. The smooth lines indicate the best-fitting ratio of omega-square models as determined by a leastsquares inversion. The resulting corner frequencies yield the stress drop values shown in each panel.

convolved spectra with a ratio of omega square models. We solve for the two corner frequencies, $f_{\mathrm{c} 1}$ and $f_{\mathrm{c} 2}$, by minimizing the least-squares residual between the computed spectral ratio, $R_{\mathrm{c}}(f)$, and the modeled ratio, $R_{\mathrm{m}}(f)$ :

$$
R_{\mathrm{m}}(f)=\frac{A_{\mathrm{o} 1}\left(1+\left(f / f_{\mathrm{c} 2}\right)^{2}\right)}{A_{\mathrm{o} 2}\left(1+\left(f / f_{\mathrm{c} 1}\right)^{2}\right)} .
$$

A grid-search method is used to determine the optimal pair of corner frequencies. For each pair of corner frequencies, we perform a regression to find the optimal least-squares amplitude ratio. We choose the corner frequency pair that yields the lowest overall misfit to the data. This method can resolve the corner frequency of the EGF event as well as the mainshock, if the former is within the usable bandwidth. 
Stress drop, $\sigma$, can be estimated assuming a circular rupture from either the corner frequency, using

$$
\sigma=M_{0}\left[\frac{f_{\mathrm{c}}}{0.49 \beta}\right]^{3},
$$

where the velocity term, $\beta$, is the shear-wave velocity near the source, assumed to be $3.2 \mathrm{~km} / \mathrm{sec}$. This formulation is consistent with the relationship between stress drop and radius

$$
\sigma=\frac{7}{16} \frac{M_{0}}{r^{3}}
$$

where $r$ is the source radius (Eshelby, 1957). Equation (3) is derived from equation (2), assuming that $f_{\mathrm{c}}=0.37 / \tau_{1 / 2}$, where $\tau_{1 / 2}$ is the half-width of the source pulse. This relationship is consistent with theoretical dislocation models (e.g., Brune et al., 1979) but associated with a fair degree of uncertainty (see Beresnev and Atkinson, 1997). We will therefore compare the stress drop values obtained here with results from studies that used the same methodology (i.e., using equation 2).

Using equation 2, the estimated corner frequencies yield the stress drop values given in Table 1 and shown in Figure 7. We obtain stress drop values for six events: the three $M$ 3.5 to 4.4 triggered earthquakes (E2, E6, E8) and their respective $M 2.1$ to 2.6 EGF events (E4, E5, E7). Stress drop values of 0.1 to $6 \mathrm{MPa}$ are obtained for all six events.

Using equation (3), a rupture radius of $6 \mathrm{~km}$ for event E1 implies a stress drop of $0.023 \mathrm{MPa}$. We note, however, that a radius of $6 \mathrm{~km}$ implies a corner frequency on the order of $0.2 \mathrm{~Hz}$, but Figure 4 reveals little evidence for a corner frequency this low. If the low-frequency spectral peak does reflect the corner frequency of E1, a value on the order of $0.5 \mathrm{~Hz}$ is suggested. This implies a stress drop of $0.36 \mathrm{MPa}$, or a radius of approximately $2.4 \mathrm{~km}$.

True uncertainties associated with stress drop estimates are very difficult to estimate and tend to be substantial. Our best resolved stress drop estimate is that obtained for E2. Estimating the range of plausible corner frequency estimates to be those that yield root mean square misfit within $20 \%$ of the optimal value, we obtain a stress drop range of 0.13 to 1.5 MPa. In light of the uncertainties associated with stress drop results, we seek only to draw general conclusions regarding the results. As Figure 7 illustrates, our results are consistent with stress drop values estimated for very small events in the Coso geothermal field (Hough et al., 1999) and aftershocks of the 1992 M 6.1 Joshua Tree, California, earthquake (Hough and Dreger, 1995). These values are, in turn, consistent with the range of values obtained by other studies (Abercrombie and Leary, 1993). Our estimated values are, however, clustered at the low end of the range inferred for earthquakes in other regions.

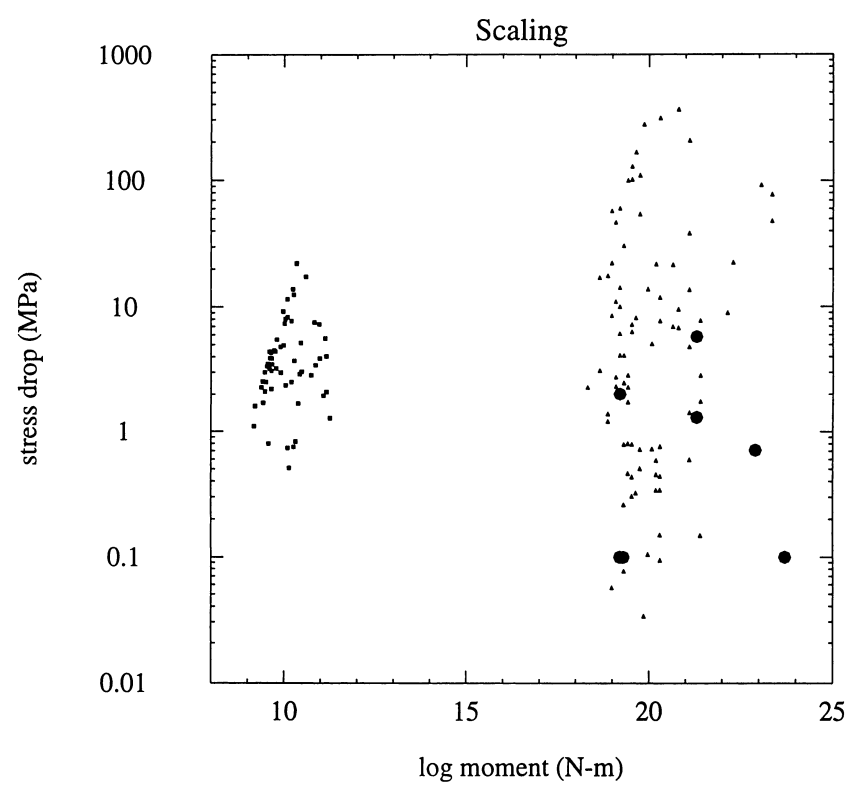

Figure 7. Stress drop values from this study (large circles) are shown along with values determined using Empirical Green's Function analysis of small events in the Coso geothermal field (small squares; see Hough et al., 1999) and of aftershocks of the 1992 Joshua Tree earthquake (small triangles; see Hough and Dreger, 1995). For event E1 we determine only a range of stress drop values suggested by the apparent dimension of the aftershock sequence from this event.

\section{Discussion and Conclusions}

In the years following the 1992 Landers earthquake, a number of studies have documented the statistical significance of remote triggered earthquakes (e.g., Hill et al., 1993; Bodin and Gomberg, 1994; Gomberg, 1996; Protti et al., 1995; Singh et al., 1998; Mohamad et al., 2000) and shown it to be associated with the dynamic loading caused by the mainshock (e.g., Gomberg and Davis, 1996; Gomberg et al., 2001). Because triggered earthquakes are observed to occur preferentially (although not exclusively) in active geothermal-volcanic regions, investigations of proposed triggering mechanisms have generally focused on those involving crustal fluids (e.g., Linde et al., 1994; Sturtevant et al., 1996; Brodsky et al., 1998).

Triggered earthquakes have, however, been documented in other tectonic environments, such as western $\mathrm{Ne}$ vada (Bodin and Gomberg 1994), Greece (Brodsky et al., 2000), and the central United States (Hough, 2001). This suggests two possibilities: (1) that preferential triggering in volcanic-geothermal areas does not result from the presence of fluids but from some other property of these regions (i.e., geothermal-hydrothermal fluids facilitate but are not required for triggering to occur) or (2) that more than one mechanism is involved with earthquake triggering.

The source properties of triggered earthquakes provide 
insight into the nature of the triggering mechanism. By definition, however, triggered events occur during times of high regional activity, so detailed investigations of source properties will inevitably be difficult. Frequently it is not possible to obtain focal mechanisms or precise locations for early triggered events, let alone to isolate the source spectra.

Fortunately, some of the earthquakes triggered by the 1999 Hector Mine earthquake occurred in a region where station coverage is fairly dense. These events were recorded by low-noise analog SCSN stations as well as broadband TriNet stations. In this study, we have focused on several events that did yield data suitable for empirical Green's function analysis. In particular, the $M 4.4$ event that occurred approximately 10 minutes after the mainshock can be analyzed in some detail. The results from this and the other events suggest that the spectra of the triggered earthquakes are consistent with those expected from brittle shear failure events; the spectra provide no evidence for an exotic source process. We calculate first-motion focal mechanisms using network data (Reasenberg and Oppenheimer, 1985) and find that they are also consistent with double-couple mechanisms (see Fig. 5). With only a small number of available first motions (e.g., 18 for E3), however, it is unlikely that one would be able to resolve anything but gross departures from double-couple mechanisms.

The stress drop values estimated in this study are somewhat low (0.1-6 MPa) compared to those obtained for small earthquakes in other tectonic settings (Fig. 7); however, the trend of the triggered events illustrated in Figure 5 follows the Brawley seismic zone, which is generally interpreted as an extensional transform zone in which stress is transferred between the San Andreas and Imperial faults via a zone of oblique extension (Johnson et al., 1994; Taylor et al., 1994). Several lines of evidence suggest that low stress drop events are to be expected in extensional regimes (e.g., Sibson, 1974; McGarr, 1984), and low values have been observed in a number of previous studies (e.g., Cocco and Rovelli, 1989; Abercrombie et al., 1995).

In cases where fluid-controlled source mechanisms have been inferred, such as for some events near Long Valley Caldera, California, stress drop values have been more grossly anomalous (with respect to expectations for brittle shear failure events) (Cramer and McNutt, 1987; Hough et al., 2000). For example, Hough et al. (2000) infer a stress drop on the order of 0.003 to $0.02 \mathrm{MPa}$ for a $M 2.7$ Long Valley earthquake that is inferred to have had a fluidcontrolled source process.

In light of the results from this study, we hypothesize that triggered earthquakes may occur preferentially in volcanic-geothermal regions because brittle shear failure occurs at relatively low stresses in high heat flow, extensional regimes. Gomberg et al. (2001) estimate that the Hector Mine mainshock generated a peak dynamic stress of approximately $1 \mathrm{MPa}$ at station SSW. If the events analyzed in this study were total stress drop events (which seems likely), then the dynamic stresses may have even exceeded the failure stress of the fault or faults. In this case, crustal fluids need not play a direct role in the triggering process to the extent suggested by earlier studies (e.g., Linde et al., 1994; Sturtevant et al., 1996). That is, we suggest that one need not appeal to an exotic fluid-controlled mechanism to explain the occurrence of remotely triggered earthquakes in geothermal and volcanic regions. It is possible, however, that fluids play some role in the initiation of all earthquakes, including remotely triggered earthquakes (see Hickman et al., 1995)

The sequence of events that followed E1 is also interesting to consider. They could reflect permanent change in local fault properties associated with the mainshock (e.g., Gomberg, 2001), a disruption in the volcanic-geothermal system that triggers tectonic events, or the local effects (i.e., the static stress change) of the first triggered event. Their overall number and magnitude distribution appear to be consistent with the expected aftershock sequence of a $M 4.5$ to 5.0 mainshock (see Fig. 2). King et al. (1994) show that the 1979 M 5.2 Homestead Valley earthquake produced static Coulomb stress changes upwards of $0.3 \mathrm{MPa}$ at distances of up to $5 \mathrm{~km}$ from the rupture, and conclude that aftershocks occur in areas where stress changes are $0.1 \mathrm{MPa}$ or higher. It might be possible to test the hypothesis of local triggering by determining whether or not their focal mechanisms are consistent with expectations for a (presumed) fault rupture and a standard Coulomb stress change model.

The temporal evolution of the Salton Sea sequence differs from that of remotely triggered earthquakes that occurred in the Mexicali Valley. Glowacka et al. (2002) present seismic, tilt, and deformation data for these events. They conclude that the passage of long-period waves did cause some disruption of fluids at depth, which gave rise to tremorlike events. In this case, slip and tilt was observed immediately after the passage of the Hector Mine seismic waves but earthquakes did not occur for several hours. (Triggered slip was also observed in the Salton Trough following the Hector Mine mainshock [Rymer et al., 2002], but it is not known when this slip occurred.) Considering the range of characteristics observed for different remotely triggered sequences, it appears likely that there might not be a single physical mechanism that accounts for all remotely triggered earthquakes.

Regardless of the mechanism associated with remotely triggered earthquakes, the observations presented in this study have implications for seismic hazard. They show that ground motions from remotely triggered earthquakes can in some cases exceed those from the mainshock. At regional distances, the overall character (i.e., frequency content and duration) of ground motion can be significantly affected by moderate local events occurring within seconds of the surface wave from a more distant mainshock. The ShakeMap representation of shaking, which maps observed peak accelerations or velocities, might be useful in identifying locations of possible remotely triggered earthquakes. 


\section{Acknowledgments}

I thank Joan Gomberg, Paul Bodin, Rachel Abercrombie, Victoria Langenheim, Ned Field, Ewa Glowacka, and an anonymous reviewer for comments and discussions that greatly improved this manuscript. This research was supported by the Southern California Earthquake Center. SCEC is funded by NSF Cooperative Agreement Number EAR-8920136 and USGS Cooperative Agreements Number 14-08-0001-A0899 and 1434-HQ97AG01718. The SCEC Contribution Number for this paper is 575 .

\section{References}

Abercrombie, R. E., and P. Leary (1993). Source parameters of small earthquakes recorded at $2.5 \mathrm{~km}$ depth, Cajon Pass, southern Californiaimplications for earthquake scaling, Geophys. Res. Lett. 20, 15111514.

Abercrombie, R. E., I. G. Main, A. Douglas, and P. W. Burton (1995). The nucleation and rupture process of the 1981 Gulf of Corinth earthquakes from deconvolved broad-band data, Geophys. J. Int. 120, 393405.

Barker, T. G. and J. L. Stevens (1983). Shallow shear-wave velocity and Q-structures at the El-Centro strong motion accelerograph array, Geophys. Res. Lett. 10, 853-856.

Beresnev, I. A., and G. M. Atkinson (1997). Modeling finite-fault radiation from $\omega n$ spectrum, Bull. Seism. Soc. Am. 87, 67-84.

Bodin, P., and J. Gomberg (1994). Triggered seismicity and deformation between the Landers, California, and Little-Skull-Mountain, Nevada, earthquakes, Bull. Seism. Soc. Am. 84, 835-843.

Brodsky, E. E., V. Karakostas, and H. Kanamori (2000). Seismicity in Greece triggered by the August 1999 Izmit, Turkey, earthquake, Geophys. Res. Lett. 27, 2741-2744.

Brodsky, E. E., B. Sturtevant, and H. Kanamori (1998). Earthquakes, volcanos, and rectified diffusion, J. Geophys. Res. 103, 23,827-23,838.

Brune, J. N. (1970). Tectonic stress and the seismic shear waves from earthquakes, J. Geophys. Res. 75, 4997-5009.

Brune, J. N., R. J. Archuleta, and S. Hartzell (1979). Far-field S-wave spectra, corner frequencies, and pulse shapes, J. Geophys. Res. 84, 2262 2272 .

Cocco, M., and A. Rovelli (1989). Evidence for the variation of stress drop between normal and thrust faulting earthquakes in Italy, J. Geophys. Res. 94, 9399-9416.

Cramer, C. H., and S. R. McNutt (1987). Spectral analysis of earthquakes in the 1989 Mammoth Mountain swarm near Long Valley, California, Bull. Seism. Soc. Am. 87, 1454-1462.

Eshelby, J. D. (1957). The determination of the elastic field of an ellipsoidal inclusion and related problems, Proc. R. Soc. Lond., Ser. A, 241, 376396.

Frankel, A., J. Fletcher, F. Vernon, L. Haar, J. Berger, T. Hanks, and J. Brune (1986). Rupture characteristics and tomographic source imaging of $M_{1} \approx 3$ earthquakes near Anza, southern California, J. Geophys. Res. 91, 12,633-12,650.

Fuis, G. S., W. D. Mooney, J. H. Healy, G. A. McMechan, and W. J. Lutter (1982). Crustal structure of the Imperial Valley Region, in The Imperial Valley, California, Earthquake of October 15, 1979, U.S. Geol. Surv. Profess. Pap. 1254, 25-50.

Glowacka, E., F. A. Nava, G. Díaz de Cossío, V. Wong, and F. Farfán, (2002). Fault slip, seismicity, and deformation in Mexicali Valley, Baja California, Mexico, after the M 7.1 1999 Hector Mine earthquake, Bull. Seism. Soc. Am. 92, 1290-1299 (this issue).

Gomberg, J. (1996). Strain changes and triggered seismicity following the $M(w) 7.3$ Landers, California, earthquake, J. Geophys. Res. 101, 751764.

Gomberg, J. (2001). The failure of earthquake failure models, J. Geophys. Res. 106, 16,253-16,263.
Gomberg, J., and S. Davis (1996). Strain changes and triggered seismicity at The Geysers, California, J. Geophys. Res. 101, 733-749.

Gomberg, J., P. Reasenberg, P. Bodin, and R. Harris (2001). Earthquake triggering by transient seismic waves following the Landers and Hector Mine, California earthquakes, Nature 411, 462-466.

Hickman, S., R. Sibson, and R. Bruhn (1995). Introduction to special section-mechanical involvement of fluids in faulting, J. Geophys. Res. 100, 12,831-12,840.

Hill, D. P., P. A. Reasenberg, A. Michael, W. J. Arabaz, G. Beroza, D. Brunmbaugh, J. N. Brune, R. Castro, S. Davis, D. DePolo, W. L. Ellsworth, J. Gomberg, S. Harmsen, L. House, S. M. Jackson, M. J. S. Johnston, L. Jones, R. Keller, S. Malone, L. Munguia, S. Nava, J. C. Pechmann, A. Sanford, R. W. Simpson, R. B. Smith, M. Stark, M. Stickney, A. Vidal, S. Walter, V. Wong, and J. Zollweg (1993). Seismicity remotely triggered by the magnitude 7.3 Landers, California, earthquake, Science 260, 1617-1623.

Hough, S. E. (2000). Inferring fault rupture length from early aftershock distributions: bridging the gap between big and small earthquakes, in Proceedings and Abstracts, 2000 SCEC Annual Meeting.

Hough, S. E. (2001). Triggered earthquakes and the 1811-1812 New Madrid, central United States earthquake sequence, Bull. Seism. Soc. Am. 91, 1574-1581.

Hough, S. E., and D. S. Dreger (1995). Source parameters of the 4/23/92 Joshua Tree, California, earthquake and its aftershocks: empirical Green's function analysis of TERRAscope and GEOS data, Bull. Seism. Soc. Am. 85, 1576-1590.

Hough, S. E., R. Dollar, and P. Johnson (2000). The 1998 earthquake sequence south of Long Valley Caldera, California: hints of magmatic involvement, Bull. Seism. Soc. Am. 90, 752-763.

Hough, S. E., J. Lees, and F. Monastero (1999). Attenuation and source properties at the Coso geothermal field, California, Bull. Seism. Soc. Am. 89, 1606-1619.

Johnson, H. O., D. C. Agnew, and F. K. Wyatt (1994). Present-day crustal deformation in southern California, J. Geophys. Res. 99, 23,95123,974 .

King, G. C. P, R. Stein, and J. Lin (1994). Static stress changes and the triggering of earthquakes, Bull. Seism. Soc. Am. 84, 935-953.

Linde, A. T., I. S. Sacks, M. J. S. Johnston, D. P. Hill, and R. G. Bilham (1994). Increased pressure from rising bubbles as a mechanism for remotely triggered seismicity, Nature $\mathbf{3 7 1}, 408-410$.

McGarr, A. (1984). Scaling of ground motion parameters, state of stress, and focal depth, J. Geophys. Res. 89, 6969-6979.

Mohamad, R., A. N. Darkal, D. Seber, E. Sandvol, F. Gomez, and M. Barazangi (2000). Remote earthquake triggering along the Dead Sea Fault in Syria following the 1995 Gulf of Aqaba earthquake $\left(M_{\mathrm{S}}=\right.$ 7.3), Seism. Res. Lett. 71, 47-52.

Mueller, C. S. (1985). Source pulse enhancement by deconvolution of an empirical Green's function, Geophys. Res. Lett. 12, 33-36.

Protti, M., K. McNally, J. Pacheco, V. Gonzalez, C. Montero, J. Segura, J. Brenes, A. Mata, and W. Schillinger (1995). The March 25, 1990 $\left(M_{\mathrm{W}}=7.0, M_{\mathrm{L}}=6.8\right)$ earthquake at the entrance of the Nicoya Gulf, Costa Rica: its prior activity, foreshocks, aftershocks, and triggered seismicity, J. Geophys. Res. 100, 20,345-20,358.

Reasenberg, P., and D. H. Oppenheimer (1985). FPFIT, FPPLOT and FPPAGE1 Fortran computer programs for calculating and displaying earthquake fault-plane solutions, U. S. Geol. Surv. Open File Rept., OF 85-0739.

Rymer, M. J., J. Boatwright, L. C. Seekins, J. D. Yule, and J. Liu (2002). Triggered surface slips in the Salton Trough associated with the 1999 Hector Mine, California earthquake, Bull. Seism. Soc. Am. 92, 13001317 (this issue).

Scientists of the U.S. Geological Survey, Southern California Earthquake Center, and California Division of Mines and Geology, (2000). Preliminary report on the 10/16/1999 M 7.1 Hector Mine, California earthquake, Seism. Res. Lett. 71, 11-23. 
Sibson, R. (1974). Frictional constraints on thrust, wrench, and normal faults, Nature 249, 542-544.

Singh, S. K., J. G. Anderson, and M. Rodriguez (1998). Triggered seismicity in the Valley of Mexico from major earthquakes, Geofis. Int. 37, 3-15.

Sturtevant, B., H. Kanamori, and E. E. Brodsky (1996). Seismic triggering by rectified diffusion in geothermal systems, J. Geophys. Res. 101, 25,269-25,282.

Taylor, B., K. Crook, and J. Sinton (1994). Extensional transform zones and oblique spreading centers, J. Geophys. Res., 99, 19,707-19,718.

Walter, W. R., J. N. Brune, and K. Priestley (1988). Observations of high frequency $P$-wave earthquake and explosion spectra compared with $\omega^{-3}, \omega^{-2}$, and Sharpe source models, J. Geophys. Res. 93, 63186324.
U.S. Geological Survey

525 S. Wilson Ave.

Pasadena, California 91106

(S.E.H.)

Seismological Laboratory

California Institute of Technology

Mail Code 252-21

1200 E. California Blvd.

Pasadena, California 91125

(H.K.)

Manuscript received 18 October 2000. 